\title{
O Programa Bolsa Família e o enfrentamento da Vulnerabilidade Social
}

\author{
Arnaldo de Jesus Aguiar Jr
}

\section{Resumo}

Atualmente, o Brasil apresenta diversos programas assistenciais que têm como objetivo diminuir as desigualdades sociais e permitir o desenvolvimento humano e social dos grupos sociais que se encontram em situação de vulnerabilidade social.

O Programa Bolsa Família (PBF) é um desses programas, que foi criado pelo governo federal com a finalidade de transferir renda para famílias em condição de exclusão social. Através do cumprimento de algumas condicionalidades, mais de 13 milhões de famílias, que atendam aos critérios de inclusão, possuem garantia de acesso aos serviços públicos de educação e saúde. (Brasil, 2012)

Entre os objetivos do programa está a promoção da independência das famílias, isto é, das famílias beneficiadas espera-se melhorias nas condições de vida e o desenvolvimento de capacidades que lhes permitam obter seu próprio sustento econômico. Em outras palavras, espera-se que as famílias conquistem autonomia e, ao mesmo tempo, encontrem as "portas de saída", como são conhecidas as desconexões com o PBF.

Uma das articulações institucionais em torno do PBF relaciona a assistência social com a educação como o caminho a ser percorrido em busca da autonomia. Segundo Amartya Sen, (2010), pode-se entender autonomia como a superação das privações de liberdade que impede os indivíduos de 
viverem de acordo com suas próprias escolhas, seus desejos e seus valores individuais.

Pobreza e exclusão social são, provavelmente, os maiores desafios das sociedades modernas, em particular da sociedade brasileira, mesmo que ao longo dos últimos sejam reconhecidos inúmeros avanços sociais, permanece grande o número pessoas em condição de vulnerabilidade social. Uma explicação possível indica que ações de enfretamento da exclusão social precisam estar envolvidas em uma rede mais ampla de propostas de bemestar social.

Segundo esta premissa, somente a partir da construção de um amplo diálogo institucional que envolva a participação do Estado, das sociedades organizadas e dos próprios cidadãos, será possível desenvolver e garantir mecanismos que permitam o desenvolvimento humano e coletivo de modo efetivo.

O diálogo inicia-se com o envolvimento do poder público, conforme estabelecido no Art. 23 da Constituição Federal de 1988 (CF-88), é de competência comum dos entes federativos, isto é, União, Estados e Municípios, a tarefa de "combater as causas da pobreza e os fatores de marginalização, promovendo a integração social dos setores desfavorecidos", no entanto, não são definidos no texto constitucional quais são os mecanismos e instrumentos que deverão ser utilizados para está atividade especifica dos entes nacionais.

A proteção estatal da parcela mais vulnerável da população e a construção de mecanismos de emancipação está presente em diferentes diplomas legais supra constitucionais, por exemplo, a Lei Orgânica da Assistência Social (LOAS) no seu artigo 25 estabelece que programas de capacitação e inserção são mecanismos de combate à pobreza, portando, os 
grupos vulneráveis da sociedade têm garantido o suporte técnico e financeiro que lhes garanta condições para o desenvolvimento humano e de cidadania.

A partir da LOAS um novo horizonte político-institucional foi estabelecido, a proposta de mudanças conceituais e estruturais contidas na lei viabilizaram e favoreceram novos diálogos intergovernamentais e interinstitucionais, portanto, foi o reconhecimento das demandas sociais. $\mathrm{O}$ status do cidadão miserável, que era de favorecido até então, recebeu um reforço de cidadania, passando a ser reconhecido como usuário portador de direitos.

Ao mesmo tempo em que estabelecia a assistência social como um dever do Estado e um direito dos cidadãos, a LOAS elevou a voz da pobreza e da exclusão social, levando a problemática dos vulneráveis para a arena das políticas públicas.

A construção desta nova arena institucional direcionada às famílias em situação de pobreza provocou nos entes uma posição proativa à procura de ações coordenadas entre diferentes graus e setores da administração pública. Isso porque as diferentes demandas necessitam de diferentes respostas, que vão além das divisões setoriais tradicionais do ambiente público.

É importante contextualizar a discussão que será desenvolvida, no Brasil, segundo Nunes (2010), o desenho organizacional tradicional do aparelho estatal reflete uma estrutura hierárquica, caracterizada pela centralidade das decisões, pelo autoritarismo, pelo excessivo planejamento burocrático, por valores patrimonialistas e por condutas clientelistas que resultam em um Estado excluidor, inibidor da participação popular nos processos decisórios, e que entende os problemas sociais como carências, muito longe da idéia de direitos sociais. 
Principalmente nas pequenas cidades, romper esta estrutura de poder tradicional que se encontra enraizada, carregada de vícios e interesses que se retroalimentam como forma de garantir a continuidade e sobrevivência de uma elite dominante, significa promover mudanças no interior burocrático do Estado, naquilo que lhe é mais vital, seus grupos de poder e suas organizações institucionais.

Um exemplo citado por Cunha (2009) apud Bichir (2011) é a ocorrência na área da assistência social o enfrentamento entre a velha política conservadora e a nova política democrática, permitindo a rivalidade de grupos distintos no curso do PBF. O desafio da coordenação burocrática está na definição da cooperação como uma atividade distinta da verticalização, que foi muito bem exposta por Abrucio, (2005), como "resultando mais em subordinação do que em parceria", neste sentido é necessária a criação de estruturas próprias de negociação entre os entes federativos.

As mudanças institucionais e organizacionais do federalismo nacional, produzidas pela CF-88, abriram espaços na agenda político-social para temas relevantes no âmbito dos direitos sociais, permitindo a transformação em direito garantido de algo que antes era tido como carência social, tratou-se de uma releitura entre o papel do Estado e da sociedade, que pode ser confirmada pela mudança do paradigma estatal, saiu de cena a exclusão social tida como um fenômeno inevitável, e surge um Estado preocupado com o bem-estar da sociedade, consagrando os direitos sociais, indicando a formação dos Welfare States.

Trata-se de uma nova definição da ação estatal na construção de "sistemas de proteção social fortemente estatizados" segundo Viana (2000, p.17), que a partir da Segunda Guerra Mundial, concretizou, inicialmente, em alguns países europeus, um novo pacto social entre o poder público e a 
sociedade por meio da construção um novo paradigma de solidariedade, basilar para a consciência cidadã.

O caminho brasileiro de proteção social é distinto do percorrido pelo Welfare State europeu, não pretendemos nos estender nas diferenças, mas para exemplificar, as diferenças políticas e de amplitude dos programas sociais são suficientes para distinguir as concepções de cada modelo. Enquanto na Europa o momento da adoção foi sequiencial a uma guerra mundial e com participação de diferentes atores políticos e sociais, no Brasil, não houve influência pós guerra e da sociedade.

No Brasil, a constituição dos direitos sociais foi acentuada no período de 1930 a 1964, por outro lado, os direitos políticos não tiveram a mesmo desempenho, neste período alternaram-se momentos democráticos e ditaduras. Aos direitos civis coube uma evolução muito lenta, segundo Carvalho (2002). A evolução dos direitos na sociedade brasileira nos remete a formação do conceito de "cidadania regulada", construído por Santos (1994): “o conceito de cidadania cujas raízes encontram-se, não em um código de valores políticos, mas em um sistema de estratificação ocupacional, e que, ademais, tal sistema de estratificação ocupacional é definido por norma legal”.

No período militar de 1964 a 1985, os números da parcela empobrecida da sociedade explodiram, identificando o tamanho da exclusão social, em benefício de uma diminuta parcela social não explorada pelos meios de produção e, ao mesmo tempo, já titulares da condição de cidadãos plenos de direitos.

Após o processo de redemocratização, iniciado na década de 1980, o novo federalismo abraçou a ampliação dos direitos sociais, e ao mesmo tempo, elevou a interdependência na gestão da implantação das políticas 
sociais. Para Abrucio (2005), cada nível de governo atuou de forma independente, processo definido como "federalismo compartimentalizado". Na década de 1990, o nível federal liderou a formação da agenda de combate à pobreza, formatando as atribuições dos demais entes federativos. Na avaliação de Almeida (2005) e Abrucio (2005), esses programas sociais provocaram a quebra da estrutura cooperativa federal da área social, sugerindo um novo modelo centralizador. No entanto, é preciso contextualizar essas análises, autores diversos enfatizam as dimensões intersetoriais dos programas sociais, para Moreno (2007), um grande tema social como pobreza demanda ações inter e intragovernamentais, em virtude da complexidade das políticas sociais contemporâneas.

A construção da cidadania é um passo adiante da implantação de políticas sociais, é também a consolidação de espaços institucionais que considerem a inclusão dos vulneráveis. Neste sentido, a organização de políticas intersetoriais nos vários níveis de governo são fundamentais para um projeto mais amplo de desenvolvimento humano e social.

Considerando o sentimento simbólico da revolução social provocada pelo $\mathrm{PBF}$, nos últimos anos, em virtude da gigantesca parcela populacional que foi incluída na roda econômica nacional e do acesso aos serviços públicos de saúde e educação, é possível identificar uma crescente melhora na consciência de cidadania nesta parcela da população.

Mais do que transformar a economia local com a elevação da renda de famílias excluídas, o PBF permite o reconhecimento do sujeito social, titular de direitos, outrora portador de situações humilhantes e vulneráveis. Justifica-se a necessidade da investigação e projeção dos efeitos a médio e longo prazo da transformação provocada pelo alívio da condição de miséria desses segmentos sociais. 
Mesmo considerando as desigualdades regionais, a implementação das diretrizes federais contidas no Programa Bolsa Família (PBF), carece de maior articulação intergovernamental, sobretudo na área da educação, para testar nosso argumento escolhemos aleatoriamente, cidades espalhadas pelo Estado de São Paulo, classificadas com diferentes graus de vulnerabilidade, a partir da classificação adotada pelo Índice Paulista de Vulnerabilidade Social, (IPVS), que comparadas com a cidade de São Paulo, permitem traça um perfil da condição atual dos beneficiários do PBF.

Segundo o pensamento de Rocha (2010, apud Bichir, 2011), “o Brasil é um país continental, (...) informações agregadas nacionalmente encobrem necessariamente situações específicas que ajudariam a entender fenômenos complexos".

Segundo Putnam (1996), leis nacionais não são capazes de provocar mudanças estruturais, uma vez que o desempenho das instituições está diretamente ligado ao ambiente político, social e econômico em que as leis se inserrem. Assim, no plano local, a efetividade das políticas públicas relaciona-se intimamente com a cultura política e institucional estabelecida em cada local.

Neste sentido, inovações constitucionais procuraram facilitar e incentivar a construção de espaços de participação pública como forma de aproximar o Estado e a sociedade civil, para isso institucionalizou diversos fóruns de debate, como por exemplo; conselhos e audiências públicas. Para Dagnino,(2002,p.10), estes espaços "visam promover o debate amplo no interior da sociedade civil sobre temas até então excluídos de uma agenda pública" e outros "que se constituem como espaços de ampliação e democratização da gestão estatal". 
A promoção dos direitos sociais estabelecidos na nova constituição nacional exige mudanças concretas na cultura organizacional pública, através da proposição de novas ações institucionais capazes de elevar a interlocução entre o poder público e os cidadãos. Práticas desarticuladas e centralizadas são inadequadas nos dias atuais; novos arranjos institucionais e corpo burocrático melhor capacitado para promover novas ações e novas práticas no atendimento da demandas sociais são a esperança da sociedade por um futuro melhor.

Desde 1990, verificam-se inúmeras experiências municipais na implementação de programas de transferência de renda condicionadas focalizando nas camadas sociais em condição de pobreza e extrema pobreza. A partir da criação do Programa Bolsa Família, em outubro de 2003, quando o governo federal concentrou outros programas distintos e espalhou pelo país este tipo de programa de transferência de renda condicionada destinado às famílias em situação de pobreza ou extrema pobreza.

O Programa Bolsa Família (PBF) que é pautado na gestão descentralizada e intersetorial que exige o cumprimento de contrapartidas por parte das famílias beneficiadas - conhecidas por condicionalidades - que são compromissos obrigatórios, tais como: inserção de crianças e adolescentes na escola, além de observar uma freqüência mínima, na área da educação; inserção de crianças, adolescentes e gestantes nos programas de saúde, na área da saúde. Os casos de não cumprimento das condicionalidades levam as famílias inadimplentes com o PBF ao desligamento.

$\mathrm{O}$ modelo adotado pelo PBF tem sido tema de várias discussões ao longo do tempo, algumas oriundas dos próprios profissionais envolvidos na implementação do programa, que resultam em questões, tais como: As famílias pobres devem cumprir as condicionalidades, como forma de 
adquirir autonomia? Estas exigências violam princípios da cidadania? A simples inclusão no programa, e o aumento da renda familiar, colabora para inclusão social destas famílias pobres? O controle da frequiência dos alunos é suficiente para garantir avanços educacionais entre os beneficiários?

Nosso desenho institucional nacional carece de maior participação popular, que poderia ser uma forma de retroalimentar a própria democracia, equilibrando a relação de forças entre governados e governante. Segundo Avritzer (2012) os processos participativos são cada vez mais constantes, possibilitando maior debate no seio da sociedade a respeito das demandas sociais.

A agenda sócio-política formada pós Constituição de 1988 incluiu a participação popular com destaque nas reformas estruturais que surgiram no embalo das conquistas sociais, ainda que tenham ocorrido, os avanços perpetuam os obstáculos ao acesso da população mais pobre aos serviços sociais. No entanto, o sucesso dos serviços sociais depende diretamente do principal interessado - o cidadão - é para este sujeito que os serviços públicos devem estar à disposição.

Os direitos sociais foram gravados no texto constitucional como pressupostos da cidadania, na teoria, quebrando os laços de favorecimento pessoal e de clientelismo que persistiam no campo da assistência social. No entendimento de Viana (2000), os usuários dos serviços públicos permanecem, na prática, submetidos às más práticas políticas que mantém afastados os valores de solidariedade e civilidade.

A orientação estatal que tem como prioridade a assistência aos mais pobres apresenta duas vertentes: a primeira se relaciona com a incapacidade deste grupo social se integrar na sociedade sem ajuda, e a segunda que 
permite uma construção simbólica em torno deste grupo de pessoas, que passam a ser classificados como uma nova categoria de pobres

No pensamento de Lautier (1999), os princípios da moralidade utilizados na defesa dos mais pobres devem ser analisados em separado dos modelos estruturais da pobreza. Enquanto a assistência está preocupada com a integração social, que identifica moralmente àqueles possuidores de direitos; o caráter redistributivo tem características compensatórias focalizadas nos mais necessitados.

O enorme volume de pobreza encontrado no território brasileiro, que de acordo com o pensamento de Lautier (1995), tem sua origem na formação no processo de desenvolvimento histórico da sociedade brasileira, que se revelou excludente, por conta das características restritivas da proteção social encontradas na trajetória nacional, tem sua persistência registrada pelos números do (sub) trabalho informal, nas famílias excluídas compostas por membros analfabetos e distantes do sistema de proteção social.

O caminho da superação da população pobre está relacionado com a mudança do status de passividade, ausente de direitos, para um papel ativo característico do agente transformador da realidade social, essa mobilidade social foi muito bem explicada por Sen (2010), a partir do acesso e do desenvolvimento das capacidades individuais adormecidas nos grupos vulneráveis.

Neste trabalho, a preocupação com a parcela vulnerável da sociedade justifica-se com a adoção da visão de liberdade produzida por Sen $(2000,2002)$, segundo a qual as limitações de uma sociedade está relacionada com a falta de oportunidades das pessoas. No caso dos pobres, é possível traçar um paralelo entre a falta de recursos financeiros, principalmente, com 
a falta de acesso aos meios que permitam o desenvolvimento pessoal, e a persistência da pobreza ao longo do tempo.

A liberdade descrita por Sen (2000) está, diretamente, relacionada com o desenvolvimento das pessoas e com o tipo de vida desejado por elas. Segundo o autor, o acesso deficiente aos serviços de saúde, educação e outros são formas de privação da liberdade e, ao mesmo tempo, comprometem a autonomia destas pessoas.

O conceito de autonomia para Pereira (2002, apud Testa et al, 2013) indica que "autonomia não é ser livre para agir como bem se entender, mas, acima de tudo, é ser capaz de eleger objetivos e crenças, valorá-los e sentirse responsável por suas decisões e por seus atos”. Sendo possível concluir que a autonomia pode ser um tipo de capacidade, que as pessoas vulneráveis estão impossibilitadas de alcançar sem o acesso aos serviços públicos de qualidade e em quantidade suficiente para o atendimento de todos os necessitados.

No entanto, nos parece distante o efetivo processo de distribuição de riqueza e de inclusão social, de alguma forma a transferência condicionada de renda não está sendo capaz de eliminar as condições de vulnerabilidade de parcela significativa da sociedade.

Acreditamos somente na educação como ferramenta capaz de reunir as condições suficientes de dinamizar outras ações complementares que elevem a qualidade de vida da população mais vulnerável e, ao mesmo tempo, contribua para a diminuição das desigualdades sociais em nosso país.

Palavras Chave: Vulnerabilidade social, Programa Bolsa Família, intersetorialidade, desigualdades sociais 


\section{Referências}

ABRUCIO, F. L. A coordenação federativa no Brasil: a experiência do período FHC e os desafios do governo Lula. Revista de Sociologia e Política, n. 24, p. 41-67, 2005.

BICHIR, Renata M. Mecanismos federais de coordenação de políticas sociais e capacidades institucionais locais: o caso do Programa Bolsa Família. 2011. Tese (Doutorado em Ciência Política)- Instituto de Estudos Sociais e Políticos, Universidade do Estado do Rio de janeiro, Rio de Janeiro,2011.

BRASIL. Constituição da República Federativa do Brasil (1988). Brasília, DF: Senado Federal, 2000 .

BRASIL. Ministério do Desenvolvimento Social e Combate à Fome (MDS). Política Nacional de Assistência Social (PNAS). Brasília: MDS, 2004.

Norma operacional básica. Brasília: MDS, 2005.

Norma operacional básica de recursos humanos do Suas (NOB/RH).Brasília: MDS, 2006.

. Lei Orgânica da Assistência Social (Loas). Brasília: MDS, 2012c.

Lei no 10.836, de 9 de janeiro de 2004. Cria o Programa Bolsa Família e dá outras providências. Brasília, Disponível em: <ftp://ftp.datasus.gov.br/ftpbolsa/download/

Ministério do Desenvolvimento Social e Combate à Fome - MDS. Secretaria de Avaliação e Gestão da Informação - SAGI. Avaliação de políticas e programas do MDS: resultados - Bolsa Família e Assistência Social. Brasília, 2007.

- Ministério do Desenvolvimento Social e Combate à Fome - MDS. Avaliação de Impacto do Programa Bolsa Família - 2a Rodada (AIBF II). Sumário Executivo. Brasília,jun. Disponível em: $<$ http://aplicacoes.mds.gov.br/sagi/PainelPEI/Publicacoes/AvaliacaodeImpactoProgramaBolsaF amiliaII.pdf $>$.

CARVALHO, Maria do Carmo B. A priorização da família na agenda da política social. In KALOUSTIAN, Silvio M. (org.). Família brasileira, a base de tudo. São Paulo-Cortez; Brasília: UNICEF, 2002.

COHN, Amélia. Desafios de uma trajetória de êxito: dez anos do PBF. In: Programa Bolsa Família: uma década de inclusão e cidadania./organizadores: Tereza Campello, Marcelo Côrtes Neri-Brasília: IPEA,2013.

NUNES, Edson de Oliveira. A gramática política do Brasil: clientelismo, corporativismo e insulamento burocrático. Rio de Janeiro. $4^{\mathrm{a}}$ Ed. Garamond. 2010

PUTNAM, R. Comunidade e democracia. Rio de Janeiro, FGV, 1996.

SEN, Amartya (1992) - Inequality Reexamined. Cambridge, MA: Harvard University Press. 